\title{
'Science and society' course is under threat at Stanford
}

Washington. Stanford University in California may have to stop awarding degrees in Science, Technology and Society (STS), following a decision by the university's school of engineering that it cannot continue to run the programme in its present form.

The crisis at Stanford has alarmed STS specialists across the United States, who feel that it is representative of attacks on their discipline from scientists who doubt its value. But faculty members at Stanford say that the problem there results chiefly from the difficulty of defending interdisciplinary work at a time of financial cutbacks.

The engineering school said last month that it would stop awarding degrees with STS as their major component in 1997, although it has since agreed to delay the change until 1998

The basic problem with the programme, says John Bravman, associate dean of the school, is that not enough senior faculty members are prepared to devote time to leading it. "We couldn't find a senior member of faculty to chair it," says Bravman. Noone questions the validity or importance of the programme, he says, but staff have other important things to do. "People really voted with their feet," he says.

Observers of the situation at Stanford say that the problems faced by the STS programme reflect a common difficulty with interdisciplinary programmes: when it comes to the crunch, specialist disciplines will always take priority.

"It was not hostility to STS but indifference and lack of an incentive structure that awards interdisciplinary work that caused our problems here," says Paul Edwards, an assistant professor on the programme.

The STS programme at Stanford has had a troubled history since it began in 1971 . Originally controlled directly by a university vice-provost, the programme was given to the Science and Humanities school when that post was eliminated. It was transferred to the engineering school in 1992 , partly to ensure greater technical input.

The programme has traditionally concentrated on undergraduate teaching. Its largest activity delivers STS courses to undergraduates who will major in science or engineering, but 50 undergraduates are on track to major in STS, and Stanford plans to stop this option after they have graduated.

A major effort by about thirty faculty members last year led to a detailed plan to extend the programme to include graduate teaching and research. But the expansion plan was rejected by the university administration, partly because of its cost and partly because of a belief that the faculty would not be prepared to provide adequate support.
STS has recently come under fire from scientists who have disparaged the ability of social scientists to mount any useful assessment of science (see, for example, Nature $375,439 ; 1995)$.

Such criticisms have not been prominent at Stanford. But some students feel that their course is a victim of a wider backlash against social science. "Programmes across

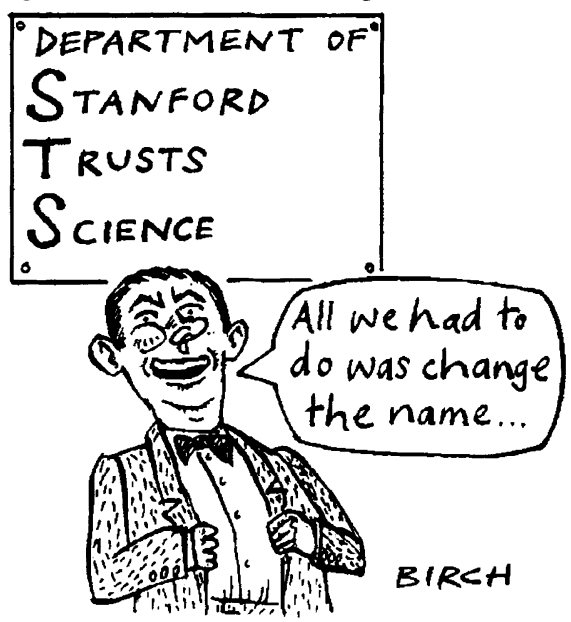

the country are having problems," says Michael Putnam, an STS student at Stanford. "Engineers don't necessarily like people taking a critical view of technology."

Trevor Pinch, chair of one of the strongest STS departments in the country at Cornell University in New York state, admits that "some of the debate has been very ill-considered". But he says that most senior science faculty respect and support STS, even if they "don't share our view of the world".

The discipline won full departmental status at Cornell five years ago - the first new department there since computer science twenty years earlier - enabling it to confer its own degrees, and thus shielding it from some of Stanford's problems.

Meanwhile, students at Stanford are fighting hard to defend the STS programme, and will discuss its future with the curriculum committee of the School of Humanities and Sciences at Stanford this week. This will lead to what could be a decisive meeting of the university senate in two weeks.

According to several officials, the STS programme may still be saved. "The question is whether a case can be made that is so compelling that they have to keep it," says Robert McGinn, acting chair of the programme. "That debate has still to run its course. I am still hoping for a favourable outcome." Gerhard Casper, the president of Stanford, told students last week that the question of continuing with degrees in STS was "still open".

Colin Macilwain
French cancer charity introduces new rules to restore probity

Paris. France's biggest medical research charity, l'Association pour la Recherche contre le Cancer (ARC), last week sought to put behind it on the financial scandal that rocked the organization earlier this year. $A$ meeting of its general assembly overwhelmingly approved a purge of the executive board and the introduction of a series of checks and balances to ensure that donations are spent on high-quality research.

ARC's continued existence has been in doubt ever since the national audit commission confirmed allegations that only a quarter of the charity's spending went to research (see Nature 379, 103; 1996). The audit commission also found evidence of fraud in the operations of companies associated with ARC.

The measures adopted last week are aimed at ensuring the charity's survival by rebuilding public confidence in its activities. The decision to oust 21 of the 26 members of the executive board is an essential step towards this goal, according to Michel Lucas, who replaced Jacques Crozemarie as chairman of ARC after the scandal.

Indeed, Lucas himself was elected chairman in the belief that he would be seen by the public as being above suspicion, as the former head of a government agency that had fought for more than a decade to expose financial irregularities at the charity (see Nature 397, 385; 1995).

At the same time, a purge of the existing board was considered necessary because many of its members had endorsed ARC's past practices and had defended the charity against earlier allegations similar to those eventually confirmed by the audit commission.

Those ousted include Dominique Bellet, director of the immunochemistry laboratory at the Institut Gustave Roussy near Paris, which had received the single largest $A R C$ grant in 1993, FF8 million (US\$XX million). To prevent such conflicts of interest recurring, the general assembly also ruled that in future board members would be prohibited from receiving ARC grants.

Last week's meeting represents a watershed in the management of ARC. But a broader impact has come from the public spotlight that the affair has thrown on the glaring lack of regulation of charities in France. For example, the government has for the first time given its own agencies broad powers to investigate charities, while charities themselves are agreeing to follow charters of good conduct. They have good reason; one fallout from the scandal at ARC has been a sharp drop in donations, not only to ARC but also to other medical research charities.

Declan Butler 